\title{
El águila regia y el más malo de los malos: El Marañón de Diego de Aguilar y Córdoba (Siglo XVI)
}

\author{
María Jesús Benites ${ }^{1}$
}

Resumen. Este trabajo propone una lectura crítica de El marañón de Diego de Aguilar y Córdoba, obra que permaneció inédita hasta el siglo XX. El libro relata los acontecimientos que rodean la desafortunada expedición que comandó Pedro Ursúa en 1559 y cuya finalidad era alcanzar las míticas tierras de Omagua y El Dorado. Aguilar y Córdoba nunca recorrió las geografías que refiere ni participó de las expediciones que narra. Este artículo inscribe al texto de Aguilar en un corpus de relatos de viajes del siglo XVI y en un proceso dinámico y vinculante definido como lecturas sedimentadas.

Palabras clave: relatos de viajes; siglo XVI; lecturas sedimentadas; río Marañón.

\section{[en] The Regal Eagle and the Most Evil: El Marañon by Diego de Aguilar y Córdoba (16th century)}

Abstract. This article focuses on El Marañon by Diego de Aguilar y Córdoba. The book refers the events that surrounded the unfortunate expedition headed by Pedro Ursúa in 1559, whose main purpose was finding the mythical lands of Omagua and El Dorado. The article states that Aguilar's text could be included in a corpus of travel accounts from the 16th-Century defined as imperial writing of the edges, on one hand, and it would be part of a dynamic process named like sedimented readings, on the other one.

Keywords: travel account; 16th Century; sedimented readings; Marañón river.

Sumario. 1. Escrituras imperiales de los confines. 2. En los desiertos remotos del Marañón.

Cómo citar: Benites, M.J. (2021) El águila regia y el más malo de los malos: El Marañón de Diego de Aguilar y Córdoba (Siglo XVI), en Anales de Literatua Hispanoamericana 50, 141-149.

Recreo, con mis palabras, una escena: Atahualpa se acerca y le muestra a Pizarro la uña de su dedo pulgar, Pizarro mira y permanece en silencio. Atahualpa está preso porque arrojó al suelo un dispositivo ajeno y que no hablaba. Para los españoles esas páginas contenían la palabra de Dios, en esa uña ahora dice DIOS, le ha pedido a uno de los soldados que se la escriba y se ha recreado mostrándoselas y escuchando siempre la misma respuesta, pero Pizarro permanece frente a ella, la palabra impresa en la uña, mudo. Atahualpa sonríe y advierte que el otro tampoco sabe, entiende, con agudeza, que leer no es cosa natural sino algo que se aprende. La sorna se apodera de la tropa, ya no es el espanto por ver el libro sagrado en el suelo, es la mirada socarrona del Inca la que golpea el orgullo del sanguinario Pizarro. Si el libro arrojado le había costado la prisión, poner en evidencia el analfabetismo del Capitán, dicta su sentencia de muerte.

Esta escena de lectura no sólo revela una inversión de los roles donde Pizarro queda expuesto, frente a la hueste que lo acompaña, en un lugar de inferioridad. Presenta además un circuito en el que ingresan la letra convertida en voz, esa palabra que entra por la vista de los que la leen y por el oído de quienes la escuchan. En esa lógica, el que permanece fuera es Pizarro, no porque ser analfabeto fuera una condición infrecuente

\footnotetext{
${ }^{1}$ Universidad Nacional de Tucumán-CONICET. Argentina.

Email: mjbenites@hotmail.com

${ }^{2}$ Siguiendo a Giorgio Agamben (2015), pienso el término dispositivo como un conjunto heterogéneo que incluye lo lingüístico y lo no-lingüístico y, al mismo tiempo, involucra discursos, instituciones, edificios, leyes, proposiciones filosóficas, etc. El dispositivo en sí mismo es la red que se establece entre estos elementos. Además, tiene una función estratégica concreta y se inscribe en una relación basada en el poder.
} 
para la época, sino porque su silencio supone un agravio tan grande como el del libro arrojado. La lectura en voz alta, aquella que comunica el escrito a quien no puede descifrarlo, es un modo de socializar un saber. No poder reconocer la palabra absoluta, ni siquiera balbucearla resignifica el castigo del Inca para transformarse en esa muerte violenta, de quien no adora al dios extraño que lleva inscripto en el cuerpo.

Es indiscutible el lugar que ocupó la escritura en el proceso de conquista, descubrimiento y colonización del Nuevo Mundo. Si bien tanto Pizarro como Atahualpa provienen de sistemas culturales diversos, ambos entienden, por disímiles circunstancias, la carga simbólica de la palabra escrita. La lectura se perfila entonces como una práctica, no sólo como una operación abstracta, sino como una puesta en juego del cuerpo, anclada en un espacio, capaz de establecer una relación consigo misma y con los otros.

\section{Escrituras imperiales de los confines}

"Al final de todo, el océano; al final del océano, nada." Séneca El Viejo

Hablo de escenas de lectura porque trabajo el proceso de representación y figuración del lector en un repertorio de relatos de viajes del siglo XVI. Congrego, bajo la denominación de "Escrituras imperiales de los confines", un corpus que refiere los viajes de descubrimiento y exploración de dos geografías indómitas y disímiles: El Estrecho de Magallanes y el Río Amazonas, lugares de naturalezas hostiles cuyos contornos imprecisos son presupuestos en la cartografía de la época. ${ }^{3}$

Recordemos que desde el primer pedido de los Reyes Católicos para que el Almirante trajera "entera relación" de los avatares de la empresa se anticipa la construcción de un lector institucionalizado, ávido de noticias sobre un mundo nuevo. Así, el primer vínculo textual que se establece entre el Viejo Mundo y las nuevas tierras no sólo es el del relato que dé cuenta de la travesía que los une sino también el conocimiento que permita sistematizar los mecanismos para administrar y someter territorios al dominio imperial. Las empresas colombinas estimularon la "curiosidad política" sobre lo que "sucedía en los viajes de descubrimiento, a lo que se veía, se negociaba y se tomaba como posesión, es decir, a las acciones y sus circunstancias, pero todavía no a una descripción en cierta medida integral de nuevos territorios" (Brendecke, 2012: 125). Durante el siglo XVI, los escritos que podemos definir como relato de viajes, el tipo discursivo cuya materia y organización dispute límites, genere tensiones y ponga en cuestionamiento su pertenencia, como si padeciera de una suerte de orfandad retórica, al discurso historiográfico.

La serie sobre el Estrecho está compuesta por las escrituras fundantes sobre la travesía de Hernando de Magallanes y relatos de empresas posteriores. Es un corpus signado por una narrativa del desamparo (Benites, 2005) que tematiza las carencias (ropa, alimentos, refugio), el abandono y el deterioro que corroe cuerpos y barcos. En esa serie, excepto el relato del viaje transoceánico de Antonio Pigafetta, quien escribe "porque la curiosidad no se vería satisfecha solamente oyendo contar las cosas maravillosas que he visto y las penalidades sufridas en la larga y peligrosa expedición que voy a describir" (2012: 191), la tarea de escribir presupone como único y excluyente lector al rey y su Consejo, son escrituras reparadoras, aquellas que buscan suturar las heridas causadas por las traiciones, los abandonos y los naufragios. ${ }^{4}$

${ }^{3}$ Cuando hago referencia a los relatos de viajes me centro en aquellos escritos alejados de la rigidez normativa y taxonómica como las relaciones geográficas o las prescripciones establecidas en las instrucciones reales, que se articulan sobre el trazado y el recorrido de un itinerario, la mayoría de las veces incierto ya que el mapa no ha terminado de diseñarse; ese trazado se ordena a partir de una cronología que da cuenta del desarrollo del viaje y del tiempo transcurrido en la expedición; las descripciones geográficas son componentes capitales; se evidencia la incorporación de digresiones asociadas a elementos o factores maravillosos; la presencia de un narrador que refiere los sucesos a partir de la propia experiencia o que explicita, en caso de una participación indirecta, las fuentes. Todos estos aspectos están atravesados, aunque no de modo excluyente, por la dimensión espacial (Benites, 2004, 2010 y 2014). Estas conclusiones sobre el relato de viajes colonial están en diálogo con trabajos, entre otros, como los de Sofía Carrizo Rueda (1997), Beatriz Colombi (2006), Elena Altuna (2002), Loreley El Jaber (2011), Jimena Rodríguez (2010 y 2018).

${ }^{4}$ El corpus sobre los viajes al Estrecho de Magallanes se aleja de las representaciones espaciales más visitadas en los estudios coloniales, son textos donde los narradores se vinculan emocionalmente con el espacio y esa vivencia está mediatizada por el asombro y el temor ante lo desconocido. El repertorio está integrado por relaciones, cartas y declaraciones escritas por quienes participaron, con distintos cargos (generales, pilotos, marineros) en las diversas expediciones que solventó la corona española a lo largo del siglo XVI: Fernando de Magallanes (1519), Jofré de Loaysa (1525), Simón de Alcazaba (1534), Francisco de Camargo (1539), Juan de Ladrillero (1557) y Pedro Sarmiento de Gamboa (1579 y 1581) para evitar que el paso entre ambos océanos fuera utilizado por corsarios ingleses y franceses. Sobre la travesía fundante de Magallanes, además del relato de Antonio de Pigafetta, quien embarcado por la curiosidad, detalla "fabulosamente" las novedades del mundo que se abre antes sus ojos, he trabajado el texto de Francisco Albo, quien minimiza la narración del acontecimiento frente a la descripción del paisaje y el de 
La otra serie, la de los viajes por el Río de las Amazonas, da cuenta de una geografía que condensa procesos de representación textual donde redundan el asombro y los móviles utópicos en torno a un inalcanzable objetivo: El Dorado, esa operación mágica, como la llama Germán Arciniegas, "que enloqueció a una Europa ávida de riquezas. Oyendo patrañas de los indios, perdió la cabeza la corte de Londres, echaron a andar por selvas y desiertos los agentes de los banqueros de Alemania, y los españoles creyeron que estaban viviendo en tiempos del Amadís de Gaula" (1972: 279).

El repertorio se inaugura con la travesía de Francisco de Orellana relatada por Fray Gaspar de Carvajal (1541) y reescrita por el Cronista Oficial Gonzalo Fernández de Oviedo (1543) ${ }^{5}$. El texto de Carvajal da cuenta de la ilusoria conquista del País de la Canela, ese espacio imaginario que, según las inciertas coordenadas que brinda Agustín de Zárate en el Libro IV de su Historia del Descubrimiento y conquista del Perú (1555) se encontraría, en algún punto de la gran selva oriental, más allá de la cordillera, más allá de los volcanes y por debajo del Ecuador ${ }^{6}$. La travesía culminó con una desvencijada embarcación que divagó durante once meses por la serpiente sin ojos, en busca de ese reino generoso en oro. Sin embargo, más inquietante y, por sobre todo, desestabilizadora, será la expedición comandada en 1560 por Pedro de Ursúa.

Es insoslayable poner en escena Viajes y navegaciones de Giovanni Ramusio (1550). El repertorio, lúcidamente trabajado por Blanca López Mariscal (2004), revela la constitución de un público renovado, que empuja los límites impuestos desde la metrópolis a la escritura en y sobre América, un público lector que lee o escucha nuevas formas de narrar y que propone nuevas maneras de interpretarlas. Las obras seleccionadas permiten no solo inferir la construcción de renovadas tradiciones y convenciones de lectura sino que además reflejan la ambición de su editor por contener en un solo objeto todos los relatos. Dimensiono esa selección ramusiana como una ordenadora del universo escriturario y del estado de conocimiento sobre el mundo. La materialidad de los volúmenes habilita pensarlos como una suerte de Atlas que se lee reconociendo nombres y rastreando puntos de referencias espaciales que incorporan, en el imaginario europeo, la reciente configuración del orbe. Los autores que habitan Viajes y navegaciones no solo proyectan la idea de un lector "oficial", inscripto en un espacio autorizado de lectura, también interpelan a otro, al alejado de la burocracia colonial que se acerca al texto movido por la curiosidad. Ramusio, en tanto editor/mediador, redefine el modo de pensar el libro al asociarlo indisolublemente y para siempre a un objeto, un relato y un autor.

Los volúmenes aglutinan, entre muchos otros escritos, la narración de Pigaffeta, la carta de Gonzalo Fernández de Oviedo al Cardenal Bembo y la Relación de Francisco Vásquez sobre la malograda expedición de Ursúa. Y aquí me detengo porque el impacto del episodio de Aguirre y sus marañones no finaliza en el contexto de producción sino que se extiende en la segunda mitad del siglo XVI y atraviesa, como ha rastreado Ingrid Galster (2011), hasta nuestro tiempo. Un capitán melancólico, una mujer tildada de hechicera y el cargo de tenedor de muertos en manos de un sujeto conflictivo al que apodan "El loco", es una combinación desafiante a los buenos augurios (más bien predestinada al infortunio de la empresa), y traza, como se anticipó, una constelación de acontecimientos que seducen a la tarea escrituraria.

Esa travesía, suerte de "relato salvaje" del siglo XVI, impone una inflexión histórica sustancial puesto que se transforma en un evento disparador de escrituras superpuestas reveladoras de un proceso que denomino lecturas sedimentadas ${ }^{7}$ en tanto acumulación interpretativa y dinámica vinculante donde adquiere relevancia

Maximiliano Transilvano, Secretario de Carlos V, para quien la travesía es una hazaña incomparable. Incluyo el testimonio del marinero Ginés de Mafra; es la voz ignota de un sujeto que ocupa el cargo de menor jerarquía en la escala del poder dentro de una flota pero cuya escritura pone a desnudo una realidad destructora de promesas. Adolece de los matices descriptivos del relato de Pigafetta o de la dramatización escénica que fluyen de la pluma de Transilvano. Mafra refiere la relación siempre tensa entre españoles y portugueses y al modo en que la sospecha y el perjurio son tramados en los barcos. En cuanto a los viajes realizados entre los años 1525 y 1535 Andrés de Urdaneta refiere la frustrante experiencia junto al Comendador Loaysa, y Juan de Mori y Alonso Veedor exponen crudamente el malogrado proyecto colonizador de Simón de Alcazaba. La serie incluye las travesías de Juan de Ladrillero y Pedro Sarmiento de Gamboa concretadas en el momento de consolidación de las instituciones imperiales en el Nuevo Mundo, período de afianzamiento de la legitimidad territorial desde un orden teológico, ideológico y político. Ladrillero racionaliza la percepción del espacio; Sarmiento de Gamboa (1580), al igual que sus antecesores, refiere travesías asociadas a la desgracia, la muerte y la desesperación.

5 El suyo es el único testimonio directo del viaje permaneció inédito hasta 1894, año en que José Toribio Medina lo incorporó a su Descubrimiento del Río de las Amazonas bajo el título de "Relación que escribió fray Gaspar de Carvajal, fraile de la orden de Santo Domingo Guzmán, del nuevo descubrimiento del famoso río Grande que descubrió por muy gran ventura el capitán Francisco de Orellana desde su nacimiento hasta salir a la mar, con cincuenta y siete hombres que trajo consigo y se echó a su aventura por el dicho río, y por el nombre del Capitán que le descubrió se llamó el río de Orellana”. El manuscrito se conserva en la Biblioteca Nacional de Madrid desde 1961 año en que fue donado por el Duque de T' Serclaes de Tilly. Toribio de Medina se basó en el manuscrito que le facilitó la familia del Duque. Además, existe una edición que corresponde al volumen I de la denominada Biblioteca Amazonas publicación dirigida por Raúl Reyes y Reyes. En tanto, la versión de Fernández de Oviedo permanecerá inédita hasta 1851.

${ }^{6}$ Resulta paradójico que, mientras el Consejo de Indias se esfuerza por obtener descripciones precisas de las posesiones transoceánicas que permitan definir el trazado cartográfico del Nuevo Mundo y contemplen las necesidades de sistematización del saber de los soberanos, funcionarios como Zárate escriban sin brindar mayores detalles o, quizás, es acertado pensar que el autor fomenta la curiosidad y el deseo antes que el dato relevante y, por cierto, inexistente.

${ }^{7}$ La categoría de lectura sedimentada deriva de un comentario realizado, durante una conferencia en el Instituto Tecnológico de Monterrey (1999), por Roger Chartier. Ante una pregunta de Blanca López Mariscal sobre los destinatarios de los relatos de viajes en el siglo XVI, el estudioso señala un proceso de sedimentación ya que son textos publicados de manera suelta, dentro de antologías, con o sin comentarios, con láminas o sin 
la presencia de un narrador en su doble figuración de autor-lector así como la inscripción textual de los destinatarios. Es un proceso activo que va dejando huellas: en cada escritura hay vestigios que remiten, a su vez, a escenas de lectura. Esta dinámica de vinculaciones textuales se inaugura con dos testimonios directos y contemporáneos a los sucesos: la carta de Gonzalo de Zúñiga y el mencionado relato, impreso por Ramusio, de Francisco Vásquez ${ }^{8}$. Escribir sobre un suceso referido con anterioridad implica un acto previo de lectura: quien reescribe se apropia de un relato ya sea para ampliarlo, corregirlo, reelaborarlo. En este proceso vinculante las temporalidades también se entrelazan y el pasado se concibe como algo en construcción nunca fijo, jamás clausurado.

Casi cuatro décadas después, en 1586, el Alcade de Quito, Toribio de Ortiguera escribe para el que llama un discreto lector a quien invita a "saborear" su Jornada del Río Marañón. Obra generosa en "crueldades, pasiones y casos de muncha lástima y compasión, y todo entre españoles, los unos contra los otros" (Ortiguera, 1981: 33) y seducida por la figura de Lope de Aguirre para quien no escatima, en evidente tensión, los calificativos de "Ira de Dios" y "Príncipe de la libertad".

Finalmente, diez años más tarde, Diego de Aguilar y Córdoba toma la pluma a "instancia de personas curiosas que sobre ello me importunaron" para narrar la "tiranía de Lope de Aguirre"10 en El Marañón. Si bien el suyo es el texto que cierra esta serie de escrituras del siglo XVI, es una obra bisagra que proyecta un debate sobre los alcances y limitaciones del discurso historiográfico y explicita un proceso dinámico que habilita pensar la relación entablada entre la demanda del público lector y las concepciones y modelos escriturarios que responden a tales preferencias.

\title{
2. En los desiertos remotos del Marañón
}

¿Parece os que es bien trocar riquezas del Pirú y del Potosí por esta tierra miserable y desventurada? Diego de Aguilar y Córdoba

Diego de Aguilar y Córdoba integra los círculos de letrados, y del poder en el Virreinato del Perú adonde llega en 1569, momento clave en el proceso de reorganización encarado por Francisco de Toledo. Aguilar tuvo cargos de importancia como el de Alguacil Mayor de Huanuco y Corregidor de Parinacochas, Vilcabamba y Humanga. En 1588, fue incorporado a la Compañía de Lanzas y Arcabuces, posición de prestigio, encargaba de custodiar a los virreyes. Pero no se limita a ser un hombre de armas cercano a las órbitas protectoras del poder en un virreinato siempre convulsionado es también, y quizás por sobre todas las otras cosas, un hombre de letras, miembro destacado de la ciudad letrada, poeta y recitador:

\author{
Tú, Diego de Aguilar, eres maestro \\ en la escuela Cirrea graduado, \\ por ser tu metro honor del siglo nuestro. \\ El renombre de Córdoba, ilustrado \\ quedará con tu lira; justa paga \\ de el amor que a las Musas has mostrado,
}

canta Clorinda, la misteriosa e ignota peruana, en su loor a la poesía donde ofrece semblanzas de los miembros de la célebre Academia Antártica que integra Aguilar. Miguel de Cervantes, siempre atento a las

ellas, con mapas o sin mapas. Es una metáfora interesante que grafica esta idea de develar esas lecturas silenciadas que no se exhiben pero de la cual se conservan rastros.

${ }^{8}$ El texto de Zúñiga es una carta que escribió a su padre, en ella incluye un romance que describe la brutalidad de Lope de Aguirre en términos de cruel matador, perro rabioso y ser endemoniado. Sobre esta expedición existen los relatos contemporáneos a los sucesos de Custodio Hernández y el de Pedrarias de Almesto a partir de la lectura del texto de Vásquez, otro ejemplo contundente de esta dinámica de apropiaciones textuales.

${ }^{9}$ Es interesante el modo en que Ortiguera expone los pensamientos de Lope y logra un proceso de autofiguración del soldado devenido en asesino y traidor: "Acabado el razonamiento y bando que habemos visto, luego se osó llamar príncipe, y su título era el más bravo y soberbio de todos cuantos se han visto hasta hoy en tirano de ninguna nación, llamándose Lope de Aguirre, La ira de Dios, Príncipe de la libertad y del reino de Tierra Firme y provincias de Chile (Ortiguera: 109, las cursivas y mayúsculas pertenecen al original). El escritor venezolano Miguel Otero Silva retoma la imagen potente de "Príncipe de la libertad" para dar título a una novela publicada por Casa de las Américas en 1982. En un pasaje Otero Silva despliega los calificativos impuestos por Ortiguera: “ iYo soy Lope de Aguirre el Peregrino!, iYo soy la ira de Dios!, !Yo soy el fuerte caudillo de los invencibles marañones!, iYo soy el Príncipe de la libertad! (238)”.

${ }^{10}$ La edición con la que trabajo ha sido publicada por la Universidad de Navarra-Biblioteca Indiana (2011) y las notas y estudio introductorio están al cuidado de Julián Díez Torres. La primera edición completa recién se publicó en el año 1990 y estuvo a cargo de Guillermo Lohmann Villena. Asimismo, existen ediciones fragmentarias de la obra como la de Emiliano Jos titulada La expedición de Ursúa al Dorado y la rebelión de Lope de Aguirre (1927), los capítulos que publica Ventura García Calderón en el Tomo V de Biblioteca de Cultura Peruana (1938) o la compilación de Mampel González y Escandell Tur quienes incluyen, en el apéndice documental, fragmentos acotados del texto de Aguilar (1981). 
novedades que provienen de las "apartadas indias"11, homenajea en La Galatea a Aguilar con versos rimbombantes:

En todo cuanto pedirá un deseo

Un Diego ilustre de Aguilar admira

Un águila real, que en vuelo veo

Alzarse a do llegar ninguno aspira (184).

Las obras que merecieron estos panegíricos no están determinadas. Es probable que, en los encuentros de la Academia Antártica, Aguilar recitara poemas propios que tampoco se conservan. Podríamos pensar que el de Aguilar es el triunfo de una voz que ha logrado maravillar más allá del pliego ya que no se registra, según Lohmann (1990), ninguna impresión de sus obras ${ }^{12}$.

En El Marañón, Aguilar escribe sobre una experiencia diferida y organiza la materia textual en tres libros a su vez divididos en capítulos que se articulan sobre el trazado y recorrido de un itinerario. Lohmann Villena en sus pesquisas sobre el manuscrito de Oviedo conjetura que este se fue perfilando en tres etapas distanciadas por extensas temporalidades: el prólogo «Al lector», de 1578; la sección con el nombre de los informantes que examinaron "la verdad de la historia" (157) en el año $1593^{13}$ y la dedicatoria a don Andrés Fernández de Córdoba de 1596. Ese trazado está ordenado a partir de una cronología que da cuenta del desarrollo del viaje y del tiempo transcurrido en la expedición. Basado casi de modo excluyente en el testimonio de Francisco Vásquez, a quien conoció en Huánuco, introduce metafóricas descripciones geográficas mientras la narración sigue un orden lineal.

Del relato de Aguilar -libro de viajes sin partidas ni retornos- se conservan, con variantes, dos copias manuscritas: una en la Universidad de Oviedo y otra en el Museo Británico. En el primer caso, tal como explica Julián Diez Torres a cargo de la más completa y rigurosa reedición, es una versión autógrafa del autor que ha cuidado la disposición de los títulos, las validaciones administrativas, es el manuscrito que cruza el océano en busca de su imprentero ${ }^{14}$. Tanto el manuscrito de Oviedo como el del Museo Británico tienen el aspecto visual de un libro con un frontispicio ilustrado, con subtítulos ampulosos y el uso de las letras capitales al comienzo de cada pliego. ${ }^{15}$

El manuscrito, ese dispositivo fascinante que nos hace emprender el camino inverso del libro al papel, que permite visibilizar los matices de la tinta, los tachones, las desgarraduras, las marcas reveladoras de la respiración interna de la escritura, de la escena fundacional del acto mismo, exhiben la clara intención de trascendencia a la letra impresa. Aguilar es, en términos más modernos, el editor de su propia obra. El manuscrito que viaja a España remite a una cartografía que involucra, en su trazado: un autor, un texto, un editor y finalmente (o quizás primero) un lector, instancias que permiten reanudar, de modo inverso, el trayecto.

Pero, además, la tarea de edición supone entregar a la comunidad la materialidad de una lectura previa. En el caso de Aguilar el acto de escribir (reescribir) la travesía de Ursúa y la rebelión de Aguirre implica compartir un enfoque interpretativo de los episodios, el trabajo de edición que autoejerce sobre su escritura es un modo otro y hasta metafórico de escenificar el acto mismo de leer no solo su propio texto, sino también el de Vásquez. Es sugerente la afirmación de de Certeau "la escritura acumula, amontona, resiste al tiempo por medio del establecimiento de un lugar, y multiplica su producción a través del expansionismo de su reproducción" (2000: 187) porque opone las dinámicas o modos de posicionarse frente a un texto: de un lado la fijeza de lo escrito, del otro la evanescencia del acto de lectura. Existe, entonces, una distancia entre el sentido asignado por el autor a su obra y la red de interpretaciones que de ella pueden tramar los lectores. Digo sugerente porque a Aguilar lo desvela el vínculo con el lector puesto que la materia textual elegida

\footnotetext{
${ }^{11}$ En "El canto de Calíope" incluido en el libro VI de La Galatea. Madrid: 1805. Tomo III.

${ }^{12}$ Aparte de El Marañón, se conversan dos fragmentos de una obra titulada Soledad entretenida, según Lohmann la obra debió ser "una especia de centón o poliantea de noticias curiosas y varias" (Lohmann Villena, 1990: XLV).

${ }^{13}$ Aguilar detalla los nombres de solo ocho testigos con sus lugares de residencia y, en algunos casos, con la fecha del fallecimiento. Aclara que hubo muchos más pero que no firmaron "por ser los que en esta jornadas se hallaron odiosos en estos reinos y en de España (157) en alusión a los numerosos procesos jurídicos que debieron enfrentar los miembros de la empresa.

${ }^{14}$ Según el registro de la página institucional "el manuscrito se destaca por la belleza de sus veintidós dibujos, la mayoría en color, de indígenas americanos y otros personajes y los cinco mapas que acompañan al texto. Se trata de un ejemplar único en el mundo, únicamente existiendo lo que probablemente sea una copia en el Museo Británico".

${ }^{15}$ Lohmann propone como hipótesis la existencia de una tercera copia manuscrita que nunca habría salido del Perú y que, muy probablemente, circuló entre los miembros de la Academia Antártica.
} 
genera tensiones. Si bien propone un relato articulado en base a lo narrativo se disculpa por introducir un personaje deleznable para el modelo imperial.

No dudo que habrá algunos que reprendan el trabajo que en esto he tomado, por ser materia no menos odiosa en nuestras tiempos que será espantosa en los por venir, y con razones de que no carecen de apariencia dirán que la historia [...] es muy principal ser guía de la vida, y que esta con las crueldades y desafueros que contiene, será despeñadero al lector con mal ejemplo y abominable desorden de vivir (160).

Una escritura que desplaza su atención a la figura de un traidor, rebelde y asesino justifica la actitud de "autor responsable" con la que Aguilar se autorrepresenta en la dedicatoria homenaje a Don Andrés Fernández de Córdoba y en el prólogo al lector a quienes les ofrece una obra donde confluyen la verdad de lo narrado, la erudición y lo estético como gesto virtuoso de la pluma:

Traen una honrada competencia la historia y la pintura. Esta con colores, figuras y sombras, poniéndonos delante los acaecimientos y casos notables pasados, y aquella explicando las particularidades de tiempos, lugares y sucesos que la pintura no puede. Yo he sido igualmente aficionado a entrambas, y a la historia como guía de la vida (según la llaman algunos), más particularmente (154).

Chartier (2005) afirma que manuscritos o impresos, los libros son objetos cuyas formas ordenan, si no la imposición del sentido de los textos que vehiculizan, al menos los usos que pueden serles atribuidos y las apropiaciones a las que están expuestos. Es interesante pensar en estos términos el prólogo puesto que más que una formalidad retórica, se transforma en un artefacto motivacional que genera y sostiene el vínculo con el lector, un lector que debe interpretar de manera lúcida y recta los sucesos referidos porque "si los malos ejemplos no se escribiesen por temor de que han de inducir al lector al maleficio antes que atemorízallo e indignar contra él, hubiera cerrado el campo a la noticia de los tiranos y homicidas que el mundo tuvo, a los cuales que aun las letras sagradas no perdonaron" (161).

En esta escritura liminar, el tono asertivo cumple, como afirmara Genette en su obra sobre los paratextos de un libro: "la función cardinal la de asegurar al texto una buena lectura. Esta fórmula simplista es más compleja de lo que puede parecer, puesto que se deja analizar en dos acciones, de las cuales la primera condiciona, sin garantizarla, la segunda, como una condición necesaria y no suficiente: 1. obtener una lectura, y 2. obtener que esta lectura sea buena" (Genette, 2001: 168) ${ }^{16}$. Es que Aguirre es un exemplum por inversión del conquistador y de su paradigmático vasallaje, la suya es una hazaña subvertida, indigna:

A lo primero se deja bien entender que el miserable y desastrado fin de Lope de Aguirre y sus secuaces no es para desear, y así no es vida para imitar porque fue muerte sin esperanza de salvación, odio de los hombres y aborrecimiento de Dios, llegando su desatino a meter las manos crueles y sangrientas en sus propias carnes que era su hija a quien amaba tanto. Demás de esto, si los malos ejemplos no se escribiesen por temor de que ha de inducir al lector al maleficio antes que atemorizallo e indignarlo contra él hubiera estado cerrado el campo a la notica de los tiranos y homicidas que el mundo tuvo [...] (160-161).

El lector entonces debe ser cómplice para "gozar de mis vigilias y defenderme de mis murmuradores" porque "no faltará quien alegue que he hecho mal en haber inmortalizado su nombre" (160). La lectura se encuentra entonces inmersa en un conjunto de obligaciones y consignas pautadas por el autor; Aguilar anhela controlar la interpretación para que su texto sea entendido en los mismos términos en los que él lo escribió. El lector no es solo una construcción, es un sujeto histórico que está obligado a saber que las atrocidades de las huestes insatisfechas no quedan sin castigo y que hasta la escritura es uno de ellos: "haciendo vivir su memoria en perpetua pena y vergüenza de sus maldades" (162). Pero Aguilar no abandona en el dogmático prólogo a su lector, lo interpela a lo largo del texto, dosifica la información para retenerlo y consolida ese vínculo cómplice y solidario: 
Yo quisiera en este lugar satisfacer al deseo de los curiosos lectores contando este viaje en particular, mas por tener el crédito dél tan falso fundamento como la relación sola destes bárbaros, no he querido entremeter cosas dudosas con las ciertas que en esta historia se han de contar (194).

Al ser el suyo un relato diferido, ajeno a los espacios limitados y limitantes de la embarcación el vínculo emocional surge de la admiración frente a determinados sucesos sorprendentes que confluyen de manera irreprimible hacia la figura de Lope de Aguirre motor que guía la escritura: "Tirano y tan cruel y malo como este jamás el mundo lo vio, no que con tan poco poder cometiese tan extraños desatinos, porque los que hasta aquí respecto de los que veremos son nada" (352).

Este proceso de construcción de Lope de Aguirre como sujeto condensador de lo hiperbólicamente negativo irá in crescendo para alcanzar su clímax en los tramos finales, el asesinato del tirano es el límite temporal del relato y del propio acto de escribir. El viaje no culmina con la llegada a un puerto, no es la escritura del embarcado que anhela el arribo, es la muerte de Aguirre la que lo clausura y la que traza una nueva cartografía referenciada por los cuerpos asesinados:

Por lo que habemos dicho mató este tirano, después que en el río Marañón se alzó hasta llegar a esta isla, veinte y cinco hombres, en los cuales entran Pedro de Orsúa [...]. Los demás fueron capitanes, alféreces, almirantes y sargentos, que este tirano hacía deshacía [...]. Mató en la Isla Margarita otros catorce de sus marañones y once de los vecinos della, con los frailes y mujeres, que sor por todos cincuenta personas las que mató hasta salir de esta isla, sin otros dos indios ladinos que allí, y a los más destos y aún a todos sin confesión. (358-359)

Pero no todo es la narración de esta travesía "desastrada e infeliz", hay que contentar al lector y el manuscrito da cuenta de un complejo circuito tanto dentro como fuera del texto: el círculo de letrados que integra la Academia Antártica, lectores/oyentes ilustres, prestigiosos, ponderan, como es propio del Siglo de Oro, la obra con poemas laudatorios. ${ }^{17}$ Aguilar incrusta en el cuerpo once poemas distribuidos en el comienzo, en el cierre de cada libro y en el final. Los hay en español italiano y francés. Los poemas, la mayoría sonetos, redundan en figuras parnasianas en consonancia con su contexto cultural, en una Lima que, según Guibovich Pérez (2013), era el principal centro editorial y la más importante plaza de distribución de libros en Sudamérica.

Los poemas amenizan la lectura, acompañan al lector, evitan su fastidium, con gracia y juegos retóricos que lo inducen al recitado, a ese acto musical de la palabra escrita pero también oralizada. Estos versos que alteran el ritmo y los tonos de la lectura, tienen un único y excluyente tópico: la ponderación del autor:

Oh fementido Aguirre, que en tu muerte

Sin merecer tu vida cosa buena

Tan gran mausoleo goza tu ceniza

Mejor que Aquiles y Alejandro en suerte

Pues un águila, regia, alta y serena

Con su divino estilo te eterniza $(420-421)^{18}$.

Con cada poema Aguilar refuerza la soberanía de su firma, construye su propia trama de contención para que El Marañón sea recibido como una obra sin fisuras y su lectura paradigma del castigo que cae sobre los que pretenden alterar el orden e instaurar, por medio de la tiranía que anula el proyecto colonizador, el caos: "Y aquí verá la recompensa que merecían y cómo el rey y sus ministros, de quien él tanto se quejaba, se habían habido con él harto benignamente, pues no le habían quitado la vida teniendo merecida tantas veces la muerte" (420).

Aguilar es el lector ejemplar del relato de Vásquez, el que quiere saberlo todo. La suya es una lectura sentenciosa que pone en un diálogo casi plagiario, su escritura con la voz del otro. De la Jornada de Omagua recupera una escena capital: la carta desvergonzada y desleal que Aguirre escribe y firma contra el Rey.

\footnotetext{
${ }^{18}$ Desde el romance que intercala Gonzalo de Zúñiga en su texto, la presencia de Lope de Aguirre en textos líricos es recurrente, versos que reafirman, en esta dinámica donde la acción de escribir remite a escenas de lectura, la condición de cruel asesino de Lope como en estos versos de La araucana de Alonso de Ercilla y Zíniga: [...] donde Lope de Aguirre en la jornada,/más que Nerín y Herodes inclemente,/pasó tantos amigos por la espada/ y la querida hija juntamente $[\ldots]$.
} 
Pienso la carta como el resumen de las escenificaciones de lectura que atraviesan la obra. Aguirre, el carnicero cruel, escribe. No oculta el descontento ni la desilusión, el propio Aguilar es consciente de ello.

Si las muertes producen asombro, el contenido de la misiva genera estupor y miedo. Los marañones que sobreviven se esfuerzan más por desprenderse de la responsabilidad de su contenido que de los asesinatos. ${ }^{19}$

Vuelvo a la escena inicial. Pizarro elucubra la muerte y el cuerpo de Atahualpa es torturado. El cuerpo de Lope, como refiere Aguilar fue: "hecho cuartos y puesto alrededor de aquella ciudad de Barquisemeto; y su cabeza se llevó a la Tocuyo y en una jaula de hierro se puso en el rollo. Llevóse la mano derecha a la ciudad de Mérida y la izquierda a la de Valencia como si fueran reliquias de algún santo" (415).

La uña desafiante de Atahualpa, que ahora se llama Francisco, la mano que escribe rebelde hasta la muerte. Las palabras siempre potencian su significación. El manuscrito de Aguilar parece proyectarse en esa mano cercenada, en la pluma que retoma la escritura, entonces el texto exclama, casi en un acto peligrosamente proclamatorio: “ ¡Libertad, libertad! ¡Viva Lope de Aguirre! (326).

\section{Referencias bibliográficas}

Albo, Francisco (1946), "Diario o derrotero del viage de Magallanes desde el cabo de San Agustín en el Brasil, hasta el regreso a España de la nao Victoria", en Colección de los Viages y descubrimientos que hicieron por mar los españoles. Martín Fernández de Navarrete. Tomo IV.

Altuna, Elena (2002). El discurso colonialista de los caminantes. Lima: Ann Arbor: CELAP y Latinoamericana editores.

Aguilar y Córdoba, Diego de (2011). El Marañón. Estudio prel. y notas a cargo de Julián Díez Torres. Navarra: Centro de Estudios Indianos, Universidad de Navarra, Iberoamericana-Vervuert. (1990). El Marañón. Ed. y estudio prel. de Guillermo Lohmann Villena. Madrid: Atlas.

Arciniegas, Germán (1972). Nueva imagen del Caribe. Buenos Aires: Sudamericana.

Barrera, Trinidad (2009), "De academias, transterrados y parnasos antárticos", América sin nombre, no. 13-14, págs. 1521.

Benites, María Jesús (2005). Con la lanza y con la pluma. La escritura de Pedro Sarmiento de Gamboa. Tucumán: Instituto Interdisciplinario de Estudios Latinoamericanos/Facultad de Filosofía y Letras/Universidad Nacional de Tucumán.

(2013), "Los derroteros teóricos de una categoría heterogénea: Los relatos de viajes al Nuevo Mundo (siglo XVI)", Moderna Sprak, vol. 107, nº 1, págs. 31-38.

(2014a), “Vigilias, fatigas y peregrinaciones': viaje, relato y desamparo en los confines del imperio", Telar, $\mathrm{n}^{\circ}$. 11-12. IIELA, págs. 80-93.

- (2014b), "La Patagonia: viajeros al confín de los infortunios", en Noé Jitrik, Cristina Iglesia y Loreley El Jaber (coords.). Historia Crítica de la Literatura Argentina. Tomo I: "Una patria literaria". Buenos Aires: Emecé, págs. 59-89.

Brendecke, Arndt (2012). Imperio e información. Funciones del saber en el dominio colonial español. MadridFrankfurt: Iberoamericana-Vervuert.

Carrizo Rueda, Sofía (1997). Poética del relato de viajes. Kassel: Reichhenberger

Colombi, Beatriz (2006), "El viaje y su relato", Latinoamérica, nº. 43. Julio-diciembre, págs. 11-35.

Chartier, Roger (2005). El mundo como representación. Historia cultural: entre práctica y representación. Barcelona: Gedisa.

De Carvajal, Gaspar (s/d) [1541]. Relación del Nuevo Descubrimiento de famoso Río Grande que descubrió por muy gran ventura el capitán Francisco de Orellana. Quito: Biblioteca Amazonas (dirigida por Toribio de Medina), vol. I. Publicación Raúl Reyes y Reyes.

De Certeau, Michel (1999). La invención de lo cotidiano, México: Universidad Iberoamericana.

El Jaber, Loreley (2011). Un país malsano. Rosario: Beatriz Viterbo.

Fernández de Oviedo, Gonzalo (s/d) [1542]. Relación del famossisimo e muy poderoso río llamado el Marañon. En Biblioteca Amazonas. Vol. I. Quito: Publicación Raúl Reyes y Reyes.

Galster, Ingrid (2011). Aguirre o la posteridad arbitraria. Bogotá: Universidad Javeriana.

Genette, Gerard (2001).Umbrales. México: Siglo XXI.

Guibovich Pérez, Pedro (2013). Lecturas prohibidas. La censura inquisitorial en el Perú tardío colonial. Lima: Fondo Editorial de la Pontificia Universidad Católica del Perú. 
Littau, Karin (2008). Teorías de la lectura. Buenos Aires: Manantial.

López de Mariscal, Blanca (2004). Relatos y relaciones de viaje al Nuevo Mundo en el siglo XVI. Madrid: Polifemo.

Mafra, G. de (2012), "Relación”, en La primera vuelta al mundo. Madrid: Miraguano/Polifemo.

Menchaca, Erika Alejandra (1999), "Las Revoluciones de la lectura: siglos XV-XX. Conferencia Magistral con Roger Chartier", Revista de Humanidades: Tecnológico de Monterrey. Disponible en: http://www.redalyc.org/articulo.oa?id=38400705

Pigafetta, Antonio (2012), "Primer viaje en torno al globo", en La primera vuelta al mundo. Madrid: Miraguano/ Polifemo.

Ortiguera, Toribio de (1981) [1586], “Jornada del Río Marañón”, en Lope de Aguirre: Crónicas. 1559-1561. Barcelona: Elena Mampel y Neus Escandell Tur, págs. 32-175.

Rodríguez, Jimena (2010). Conexiones transatlánticas. México: El Colegio de México.

----------, ------- (2018). Escribir desde el océano. La navegación de Hernando de Alarcón y otras retóricas del andar por el nuevo mundo. Madrid-Frankfurt: Iberoamericana-Vervuert.

Sarmiento de Gamboa, Pedro (1950) [1580-1590]. Viajes al Estrecho de Magallanes. Buenos Aires: Emecé. Ed. y notas de Ángel Rosenblat. Intr. de Armando Braun Menéndez. Dos tomos.

Transilvano, Maximilano (2012) [1522], “Carta de relación”, en La primera vuelta al mundo. Madrid: Miraguano/Polifemo. 